sequences which precede ether administration. These hypotheses receive support from two studies. Jacobs \& Sorenson (1969) found that passive avojdance learning in Swiss-Webster mice was retarded by immersion in hot or cold water for $0-2$ sec after a trial. Elias \& Simmerman (1970) found that a blast of air after daily discrimination trials resulted in an increase in swimming times and an increase in errors for Strain C57BL/6J under exactly the same conditions as the present experiment, with the exception of the ether treatment. The fact that aversive stimulation has a deleterious effect on learning suggests that decrements in learning following postrial etherization cannot be solely attributed to the CNS-depressing effects of ether.

There was no difference in errors for Ss that received ether as opposed to control handling before each trial. However, Ss of both strains showed significantly faster swimming times on Block 1 as a function of pretrial etherization. This suggests that the stimulating effects of light ether anesthesia, described by Cherkin (1968b), enhanced drive or arousal level but did not affect learning or memory perse. The difference in swimming times between ether and control Ss was much less for the $\mathrm{DBA} / 2 \mathrm{~J}$ strain. In fact, the $\mathrm{DBA} / 2 \mathrm{~J}$ mice that received pretrial etherization actually showed an increase in swimming time from Block 1 to Block 3. The fact that the DBA/2J strain was much less affected by pretrial etherization than the C57BL/6J strain may be related to a naturally higher level of arousal or a greater responsiveness to water escape incentive in the former strain which was not increased appreciably by pretrial etherization. This hypothesis receives support from the observation that swimming times were faster for the $\mathrm{DBA} / 2 \mathrm{~J}$ controls than for the C57BL/6J controls for Experiments 1 and 2 . These data suggest that pretrial etherization may provide a useful tool for studying strain differences in drive or arousal mechanisms.

\section{REFERENCES}

ABT, J. P., ESSMAN, W. B., \& JA? VIK, M E. Ether-induced retrograde amnesia for one-trial conditioning in mice. Science, 1961, 133, 1477-1478.

ALPERN, H. P.. \& KIMBLE, D. P Retrograde amnesic effects of diethyl ether and bis(trifuluorethyl) ether Journal of Comparative \& Phvsiological Psychology, 1967, 63, 168-171.

CHERKIN, A. Retrograde amnesia: Role of temperature, dose, and duration of amnesic agent. Psychonomic Science. 1968a, 13, 255-256.
CHERKIN, A. Molecules, anesthesia, and memory. In $A$. Rich and $N$. Davidson (Eds.) Structural chemistry and molecular biology. San Francisce: molecular biology. San
Freeman, 1968 b. Pp. 325-342.

ELI AS, M. F., \& SIMMERMAN, S. J. Strain differences in memory and incentive as a function of external stimulation. Psychonomic Science, 1971, 22, 189-191. ESSMAN, W. B., \& JARVIK, M. E. Impairment of retention for conditioned response by ether anesthesia in mice. Psychopharmacologia (Berlin), $1961,2,172-176$

HERZ, M. J., PEEKE, H. V. S., \& WYERS E. J. Amnesic effects of ether and electroconvulsive shock in mice. Psychonomic Science, 1966, 4, 375-376. JACOBS, B. L., \& SORENSON, C. A Memory disruption in mice by brief posttrial immersion in hot or cold water. Journal of Comparative \& Physiological Psychology, 1969,68, 239-244.

JARVIK, M. $E$. The influence of drugs on memory. In H. Steinberg, V. S, de Reuck, and J. Knight (Eds.), Animal behavior and drug action. Boston: Little-Brown 1964. Pp. 44-61.

McGAUGH, J. L. Time-dependent processes memory storage. Science, 1966, 153. 1351-1358.
PEARLMAN, C. A., JR. Similar retrograde amnesic effects of ether and spreading cortical depression. Journal of Comparative \& Physiological Psychology. $1966,61,306-308$

PEARLMAN, C. A., SHARPLESS, S. K.. \& JARVIK, M. E. Retrograde amnesia produced by anesthetic and convulsant agents. Journal of Comparative \& Physiological Psychology, 1961, 54, 109-112.

WALLER, M. B., WALLER, P. F., \& BREWSTER, L. A. A water maze for use in studies of drive and learning. Psychological Reports, 1960, 10 , 147-150.

WIMER, R. E. Bases of a facilitative effect upon retention resulting from posttrial etherization. Joumal of Comparative \& Physiological Psychology, 1968, 65, 340-342.

WIMER, R. E, SYMINGTON, L. FARMER, H., \& SCHWARTZKROIN, P. Differences in memory processes between inbred mouse strains C57BL/6J and DBA/2J. Journal of Comparative \& Physiological Psychology, 1968, 65, $126 \cdot 131$.

WINER, B. J. Statistical principles in experi mental design. New York: McGraw-Hill. 1962.

\title{
Tricarboxylic acid cycle levels following avoidance acquisition by rats*
}

\author{
ARNOLD D. SHERMAN† \\ Carleton University, Ottawa, Ontario, Canada
}

To gain further information on the relationship between intermediary metabolism and acquisition, rats were trained in a two-trial avoidance task and sacrificed for chemical analysis. Rough quantitative measures of five acids of the tricarboxylic acid cycle were obtained. After the second trial, Ss were assigned to groups by their behavior: passive avoidance, approach, or active avoidance. Kruskal-Wallis analyses of variance indicated that differences in citrate and in succinate levels were reliable. It cannot be concluded that the results were associated with learning.

Because numerous drugs affecting intermediary metabolism (e.g., amphetamines, phenothiazines) have been shown to have significant behavioral effects, measurement of some intermediary metabolites during a behavioral situation might be informative in elucidation of the physiological mechanisms underlying such behavior. Since the tricarboxylic acid cycle (TCAC) is so closely related to numerous metabolic processes, measurement of some of the substrates of this cycle would seem to be appropriate to tracing metabolic changes occurring during a behavioral task. Even if the relevant metabolic changes do not directly involve the

*This study was part of a dissertation submitted to the Faculty of Graduate Studies, Carleton University, in partial fulfillment of the requirements for the $\mathrm{PhD}$ degree and was supported by funds from the Department of Psychology and by Grant PA 242 from the National Research Council to A. J. Ray, Jr.

tPresent address: $\mathbf{8 3 0 1}$ Ridge Boulevard, Brooklyn, N.Y. 11209.
TCAC, the importance of this cycle to almost all synthetic tasks might allow the enumeration of the relevant reactions by the use of metabolic inhibitors.

If transient metabolic changes are to be studied, a rapidly acquired task would be most appropriate. For this reason, a one-trial avoidance task was used. This situation allows exact comparisons to be made because all Ss receive the same external conditions (CS, US, ITI, and second CS) regardless of their behavior. Because these conditions are constant for all Ss, the probability that observed metabolic changes were associated with external conditions was low.

\section{SUBJECTS}

The Ss were 15 male Sprague-Dawley rats about 55 days old and weighing between 180 and $200 \mathrm{~g}$ upon arrival. All Ss were group housed and had free access to food and water until $24 \mathrm{~h}$ before testing. Ss were handled daily and individually placed 
in the apparatus for $3 \mathrm{~min}$ daily for each of 5 days.

\section{Apparatus}

The apparatus used was a one-way adaptation of the shuttlebox described by Ray (1966). The CS consisted of a $15 \cdot \mathrm{mA}$ pilot light (12 V, USA No. 233) covered with a clear plastic lens and an 80- $\mathrm{dB}$ tone presented through a 3-in.-diam Midland speaker ( 8 ohms, $0.1 \mathrm{~W}$ ) by a Grass electronic stimulator (Model SD-5C).

A retractable aluminum door was placed in the gap between the center cornice and the grid floor. The door was mounted on a track which extended $1 / 4$ in. above the grid floor and out of the apparatus and was retracted by means of a line attached to it. Upon release of the line, the door returned to the closed position, preventing $S$ from changing compartments.

\section{Procedure}

Twenty-four hours prior to the beginning of training, all $S$ s were deprived of food but were allowed free access to water. At the beginning of training, $S$ was placed in the compartment containing the CS. Five seconds were allowed to elapse for habituation and to allow $E$ to prepare. A trial began with the onset of the compound $\mathrm{CS}$ and simultaneous retraction of the door. The CS was presented for $8 \mathrm{sec}$. After $8 \mathrm{sec}$, a blast of air at 35 psi was delivered through the apparatus. The $C S$ and the US both terminated when $S$ had run from the compartment containing the $\mathrm{CS}$ to a line 9 in. from the center. After $S$ had escaped into the positive compartment, $\mathrm{S}$ was allowed to remain there for an ITI of 30 sec with the door between the compartments closed. During this interval, the air solenoid was disconnected to prevent an air blast on the second trial.

The second trial began with $E$ lifting $S$ out of the positive chamber by hand. Five seconds were allowed to elapse with $S$ in the negative chamber, and the CS was presented for $8 \mathrm{sec}$ regardless of the animal's behavior. Again, the door was retracted with the $\mathrm{CS}$ onset. After $8 \mathrm{sec}, \mathrm{S}$ was removed from the apparatus and immersed in liquid nitrogen.

After all Ss for one session were run and sacrificed, chemical analysis was performed. The frozen brain was removed from the skull and dissected. The hemispheres were removed and a $1-\mathrm{mm}$ slice was removed by coronal sectioning and discarded. Another slice was removed by coronal section about $6 \mathrm{~mm}$ posterior to the first section. This large slice was cleaned and weighed, and the extraction was begun. A liver sample was also obtained at this time and was treated in the same manner as the brain sample.
Table 1

Kruskal-Wallis Analyses of Variance by Ranks

\begin{tabular}{llc}
\hline \multicolumn{1}{c}{ Substrate } & df & H \\
\hline Citrate & 2 & $11.57^{* *}$ \\
Q-ketoglutatate & 2 & 3.85 \\
Succinate & 2 & $7.24^{*}$ \\
Pyruvate & 2 & 3.43 \\
Lactate & 2 & 3.50 \\
\hline
\end{tabular}

$* p=.05 . * * p=.01$

The tissue was homogenized by hand and added to at least 30 volumes of acetone. Five normal $\mathrm{HCl}$ was then added to the acetone until a protein precipitate appeared. Then, $1 \mathrm{ml}$ of $\mathrm{HCl}$ in excess was added. The tissue was allowed to stand in this mixture under refrigeration overnight. After $18 \mathrm{~h}$, the acetone- $\mathrm{HCl}$ was decanted, and two 5-ml washes of acetone were added, each standing for $5 \mathrm{~min}$. The extract and the washes were combined and allowed to evaporate to dryness. After evaporation, ethanol :water (1:1 by volume) was added and the resulting solution was evaporated until approximately .100 microliters remained. This volume was applied to a chromatography strip in 5-microliter aliquots and air-dried. The chromatography strip was an inert plastic strip, at least $2 \times 20 \mathrm{~cm}$, covered with a 300-micron layer of cellulose MN 300 . The strips were stored in a closed container and dried before use.

After spotting the ethanol:water mixture within a $7 \cdot \mathrm{mm}$ circle and drying the plates, $E$ developed the strips in a chamber saturated with solvent. The solvent was chloroform:t-amyl alcohol :formic acid (27:5:5 by volume) and was allowed to saturate the chamber for at least $1 \mathrm{~h}$ before the beginning of development. The strip was allowed to develop for $45 \mathrm{~min}$, resulting in a $15-\mathrm{cm}$ run in all cases.

After development, the plates were allowed to air-dry overnight and then sprayed with 2,4-dichloroindophenol ( $\mathrm{Na}$ derivative) until red spots appeared against a blue background. The substrate levels were quantitatively determined by planimeter record of the spot areas. Substrates were identified by typical Rf values.

The technique has several systematic errors. There is, for example, an error of about $5 \%$ in weight determination based on spot area. The extraction technique, as performed by the present $E$ on serum, resulted in recoveries of $88 \% \cdot 108 \%$. A similar error could be expected in the present study.

The Ss were divided into three groups on the basis of their behavior on the second trial. Group 1 consisted of those Ss which approached the CS on the first trial and failed to approach the CS on the second trial, thus performing a passive avoidance response. Group 2 consisted of all Ss which approached the CS on the first trial and approached the CS on the second trial, showing no change in gross behavior. Group 3 was made up of those Ss which approached the CS on the first trial and performed an active avoidance response on the second trial. An approach response was recorded only if $S$ assumed a two-legged stance with the head in the area of the CS. Three Ss failed to approach the CS on the first trial and were dropped from the experiment at that point.

\section{RESULTS}

A correlation between total extracted substrate from brain and from liver for each $S$ was used to determine whether factors other than general activity level could be responsible for differences between groups: The rho correlation between an S's rank on total brain extract and total liver extract was .02 $(\mathbf{p}<.90)$. Thus, brain and liver reactions in this situation may have been relatively independent.

Kruskal-Wallis analyses of variance by ranks were performed on levels of individual acids in brain by groups (see Siegel, 1956). As seen in Table 1, differences did exist, with differences in citrate and in succinate metabolism being the most reliable.

In light of these differences, the comparison between Groups 2 and 3 may be important, in spite of the small number of animals in each group. These groups had identical training and, on the second trial, both performed a motor response-Group 2 toward the CS and Group 3 away from the CS. For citrate and for succinate, differences had a chance probability of $<.03$ by the Mann-Whitney U test. DISCUSSION

It cannot be concluded that the brain metabolic changes (especially in succinate and citrate) were associated with learning. It also remains to be demonstrated that the metabolic changes were associated with the behavioral change and that the behavioral changes themselves were not associated with chance responding. The data do indicate that further studies of TCAC activity might prove valuable in determining more associations between brain metabolism and acquisition.

\section{REFERENCES}

RAY, A., JR. Shuttle avoidance: Rapid acquisition by rats to a pressurized air unconditioned stimulus. Psychonomic Science, 1966, 5, 29-30.

SIEGEL, S. Nonparametric statistics. Toronto: McGraw-Hill, 1956. P. 184. 